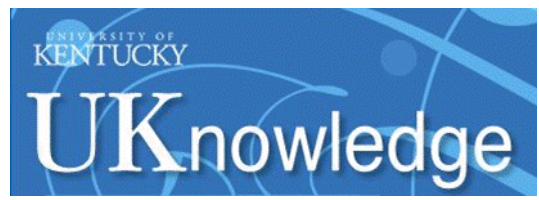

University of Kentucky

UKnowledge

\title{
Emerging Roles of Xenobiotic Detoxification Enzymes in Metabolic Diseases
}

\author{
Michael C. Petriello \\ University of Kentucky, michaelcpetriello@gmail.com \\ Jessie B. Hoffman \\ University of Kentucky, jessie.hoffman@uky.edu \\ Andrew J. Morris \\ University of Kentucky, a.j.morris@uky.edu \\ Bernhard Hennig \\ University of Kentucky, bhennig@uky.edu
}

Follow this and additional works at: https://uknowledge.uky.edu/superfund_facpub

Part of the Environmental Health and Protection Commons, Medical Pathology Commons, and the Nutritional and Metabolic Diseases Commons

Right click to open a feedback form in a new tab to let us know how this document benefits you.

\section{Repository Citation}

Petriello, Michael C.; Hoffman, Jessie B.; Morris, Andrew J.; and Hennig, Bernhard, "Emerging Roles of Xenobiotic Detoxification Enzymes in Metabolic Diseases" (2017). Superfund Research Center Faculty Publications. 2.

https://uknowledge.uky.edu/superfund_facpub/2

This Review is brought to you for free and open access by the Superfund Research Center at UKnowledge. It has been accepted for inclusion in Superfund Research Center Faculty Publications by an authorized administrator of UKnowledge. For more information, please contact UKnowledge@lsv.uky.edu. 


\section{Emerging Roles of Xenobiotic Detoxification Enzymes in Metabolic Diseases}

Digital Object Identifier (DOI)

https://doi.org/10.1515/reveh-2016-0050

\section{Notes/Citation Information}

Published in Reviews on Environmental Health, v. 32, issue 1-2, p. 105-110.

@2017 Walter de Gruyter GmbH, Berlin/Boston.

The copyright holder has granted the permission for posting the article here. 


\section{Review}

\section{Michael C. Petriello, Jessie B. Hoffman, Andrew J. Morris* and Bernhard Hennig* Emerging roles of xenobiotic detoxification enzymes in metabolic diseases}

DOI 10.1515/reveh-2016-0050

Received September 15, 2016; accepted September 30, 2016; previously published online November 12, 2016

\begin{abstract}
Mammalian systems have developed extensive molecular mechanisms to protect against the toxicity of many exogenous xenobiotic compounds. Interestingly, many detoxification enzymes, including cytochrome P450s and flavin-containing monooxygenases, and their associated transcriptional activators [e.g. the aryl hydrocarbon receptor (AhR)], have now been shown to have endogenous roles in normal physiology and the pathology of metabolic diseases. This mini-review will focus on two such instances: the role of flavin-containing monooxygenase 3 (FMO3) in the formation of the cardiometabolic disease biomarker trimethylamine-N-oxide (TMAO) and the role of AhR as a sensor of endogenous ligands such as those generated by the gut microbiota. Understanding the roles of xenobiotic sensing pathways in endogenous metabolism will undoubtedly lead to a better understanding of how exposure to environmental pollutants can perturb these physiological processes.
\end{abstract}

Keywords: cardiovascular disease; dioxin; FMO3; metabolic pathologies; TMAO.

\footnotetext{
*Corresponding authors: Andrew J. Morris, Superfund Research Center, University of Kentucky, 900 S. Limestone Street, Lexington, KY 40536, USA; Lexington Veterans Affairs Medical Center, Lexington Kentucky, USA; and Division of Cardiovascular Medicine, College of Medicine, University of Kentucky, Lexington, KY 40536, USA, E-mail: a.j.morris@uky.edu; and Bernhard Hennig, Superfund Research Center, University of Kentucky, 900 S. Limestone Street, Lexington, KY 40536, USA; and Department of Animal and Food Sciences, College of Agriculture, Food and Environment, University of Kentucky, Lexington, KY 40536, USA, Phone: +1 859-218-1343, Fax: +1 859-257-1811, E-mail: bhennig@uky.edu

Michael C. Petriello: Superfund Research Center, University of Kentucky, 900 S. Limestone Street, Lexington, KY 40536, USA; Department of Animal and Food Sciences, College of Agriculture, Food and Environment, University of Kentucky, Lexington, KY 40536, USA; and Lexington Veterans Affairs Medical Center, Lexington Kentucky, USA

Jessie B. Hoffman: Superfund Research Center, University of Kentucky, 900 S. Limestone Street, Lexington, KY 40536, USA; and Department of Pharmacology and Nutritional Sciences, College of Medicine, University of Kentucky, Lexington, KY 40536, USA
}

\section{Introduction}

Humans are exposed to multiple endogenous and xenobiotic compounds that if left unmodified and excreted could impact cellular physiology, leading to detrimental pathological outcomes. Fortunately, mammalian systems have evolved multiple signaling systems, including the wellstudied nuclear factor (erythroid-derived 2)-like 2 (Nrf2) and aryl hydrocarbon receptor (AhR) pathways, among others, which aide in the detoxification, elimination, and increased endogenous antioxidant buffering capacity against the toxicity of chemical compounds. Two major classes of detoxification enzymes, cytochrome P450s (CYPs) and flavin-containing monooxygenases (FMOs), are known to modify multiple drugs and environmental pollutants, generating more readily excreted polar metabolites, but emerging data now implicate these xenobioticmetabolizing enzymes in the metabolism of endogenously formed or diet-derived compounds that are themselves associated with disease pathologies. Here, we briefly outline the importance of studying such endogenous roles by focusing on FMO3's broad impact on metabolism and cardiovascular disease risk as well as the interplay between gut microbiota and AhR-CYP1A1 signaling.

\section{Emerging roles of FMO3 in cardiometabolic disease}

Flavin-containing monooxygenases are a major class of enzymes responsible for oxidizing multiple substrates including many commonly administered amine- and sulfate-containing drugs $(1,2)$. FMO3 is the primary isoform found in the liver, and thus has garnered much attention because of its role in drug metabolism and drug-drug interactions. FMO3 expression is modulated by multiple transcription factors (e.g. AhR, FXR, C/EBPbeta) and steroid hormones, but inter-species differences are evident (3-6). Interestingly, female mice and humans display significantly more FMO3 at baseline levels than their male counterparts, although the differences in mice are more robust (7). Multiple genetic mutations in the FMO3 gene locus 
have been discovered in human populations, with the most severe causing a loss of function of the enzyme product in an autosomal recessive manner. The most obvious phenotypic difference in rare individuals who are homozygous for loss of function of FMO3 alleles is a distinct fishy body odor known as trimethylaminuria, named for the malodourous compound, trimethylamine (TMA), that FMO3 normally quickly metabolizes (8). It is now known that the formation of TMA and oxidation product trimethylamine$\mathrm{N}$-oxide (TMAO) is reliant on the gut microbiota-dependent metabolism of dietary precursors such as choline and carnitine $(9,10)$. Previously, it was believed that the FMO3 product TMAO was a benign compound, but emerging data now implicate TMAO's importance as a biomarker or possibly causative contributor to coronary artery disease, diabetes, and kidney disease risks (7, 10-13).

Circulating TMAO is garnering much attention as a biomarker of multiple cardiometabolic diseases including coronary artery disease (CAD), type 2 diabetes, and kidney disease (7, 10-12, 14-17). First implicated as a biomarker of human disease in 2013, Hazen's group at the Cleveland Clinic described that TMAO could be formed in a gut-microbe-dependent manner from dietary sources like eggs, and also showed that people with higher TMAO were more likely to experience a heart attack or a related ailment (10). This work has been widely cited because it was one of the first studies to show that bacteria living in the gut could create a compound that, at the least, was a biomarker of the leading cause of death in the United States, cardiovascular disease. Since then, there have been some reports implicating TMAO as a causative agent of inflammation and disease pathology (12, 17-19). For example, TMAO was shown to alter nuclear factor-kappa $\mathrm{B}$ (NF-KB) signaling in both endothelial and smooth muscle cells, leading to a pro-inflammatory response (19). Not all data currently support this hypothesis that increased TMAO is detrimental to human health. In fact, seafood is known to be a good source of TMAO and related substrates, but dietary intake of certain fish has been linked to protection against cardiovascular disease. Thus, other factors may be more important in mechanistically explaining this observed link between TMAO and human disease, such as alteration of gut microbiota diversity or regulation of FMO3.

Although TMAO may have its own pro-atherosclerotic or pro-inflammatory characteristics, emerging evidence now implicates a role of FMO3 in cardiometabolic disorders independent of TMAO. Using genetically modified mouse models or anti-sense oligo nucleotide silencing (ASO), at least three independent laboratories have now shown that FMO3 plays important roles in reverse cholesterol transport, glucose and insulin signaling, lipid metabolism, and metabolic dysfunction $(7,9,20$, 21). Shih et al. showed that a decrease in FMO3 lowered circulating TMAO as well as reduced plasma and liver levels of glucose and lipids in a mouse model highly susceptible to atherosclerosis (21). Similar work extended these observations to show that ASO-mediated silencing of FMO3 altered cholesterol transport; FMO3 downregulation resulted in an apparent preference for transintestinal cholesterol excretion (TICE), promotion of macrophage reverse cholesterol transport (RCT), a repression of biliary cholesterol levels, and decreased intestinal cholesterol absorption (20). Finally, multiple epidemiological and preclinical studies have shown that metabolic disorders, such as diabetes, and cardiovascular disease/atherosclerosis are interconnected, and FMO3 may be a critical mediator of these observed associations. In a mouse model of diabetes, FMO3-ASO treatment resulted in increased glucose sensitivity via alterations of key metabolic control genes including FOXO1 and SREBP-2 (7). Additionally, it was shown that FMO3 can be inhibited by insulin in vitro, and FMO3 expression was increased in obese/insulin-resistant clinical patients (7). Most of the discussed work implicating FMO3 and cardiometabolic signaling was completed using ASO technology in mouse models highly susceptible to diseases (e.g. LDLr -/- or LIRKO mice), so it will be important to recapitulate these findings in wild-type and FMO3 knockout animals. Multiple research groups have shown that AhR may transcriptionally regulate FMO3, which may provide evidence linking AhR, TMAO, and cardiometabolic diseases.

\section{Emerging roles of AhR signaling in metabolic function}

AhR is a ligand-activated transcription factor involved in xenobiotic metabolism with a binding pocket capable of interacting with a variety of endogenous and exogenous ligands (22). AhR was first characterized as a receptor for dioxins like 2,3,7,8-tetra-chlorodibenzo-p-dioxin (TCDD), but additional environmental agonists including halogenated hydrocarbons (HAHs) and polycyclic aromatic hydrocarbons (PAHs) have also been identified and studied. In its inactive state, AhR is located within the cytoplasm as a component of a large protein complex that includes a dimer of heat shock protein 90 (Hsp90) and the co-chaperone protein X-associated protein 2 (XAP2) $(22,23)$. Upon binding of an agonist, the AhR complex translocates to the nucleus where it dimerizes 
with the AhR nuclear translocator (ARNT). Upon this dimerization, AhR and ARNT can bind to specific DNA sequences contiguous to promoter regions called "xenobiotic responsive elements" (XREs) (22, 23). The subsequent recruitment of co-activators by AhR and ARNT can lead to the transcription of numerous genes involved in xenobiotic metabolism such as the phase I, phase II, and phase III drug-metabolizing enzymes (22). The primary function of this increase in expression and induction of drug-metabolizing enzymes is to assist in the metabolism and clearance of the initial AhR ligands; however, it has been observed that during this metabolism, certain proinflammatory pathways can be activated that contribute to the development of chronic inflammatory diseases (22-24).

Dioxin-like pollutants, including PCBs, are potent ligands of $\mathrm{AhR}$, and their interaction can influence outcomes related to cardiometabolic disease $(25,26)$. Within vascular endothelial cells, activation of AhR by coplanar PCBs (e.g. PCB 126 and PCB 77) contributes to a CYP1A1-facilitated uncoupling mechanism resulting in an increase in reactive oxygen species (ROS) (27). Subsequently, these elevated levels of ROS contribute to dysregulation of the cellular redox status, which can lead to activation of NF- $\kappa B$ and induction of pro-inflammatory molecules, including cytokines, chemokines, and cell adhesion molecules $(28,29)$. Preclinical data have indicated that these PCB-induced pollutants increase ROS, and activation of pro-inflammatory pathways can contribute to the development of atherosclerosis and cardiovascular diseases $(28,29)$. There are also a few human studies linking genetic polymorphisms in key AhR-related genes (e.g. CYP1A1) to increased risk of cardiovascular disease and metabolic disease risk factors $(30,31)$.

While AhR has been classically characterized as a mediator of xenobiotic metabolism of organic pollutants, emerging research now points to numerous other metabolic and developmental impacts of AhR and CYP1A1 (32). Much of our understanding of the endogenous functions of AhR comes from studies involving AhR null mice. AhR null mice, as expected, are resistant to dioxin-like pollutant toxicity (33). However, compared to their wild-type counterparts, AhR null mice have smaller livers, delayed growth, and exhibit cardiovascular and fertility abnormalities, thus suggesting roles of AhR that extend beyond xenobiotic metabolism $(34,35)$.

Interestingly, AhR null mice also display altered energy expenditure and fibroblast growth factor 21 (FGF21) expression, changes in body weight, and differential glucose/insulin signaling (36-40).
It has been observed that $\mathrm{AhR}$ activation can occur in the absence of exogenous ligands, thus suggesting the presence of endogenous ligands of AhR (41). Several of the known endogenous ligands of AhR are derived, via various mechanisms, from the amino acid tryptophan. For example, 6-formylindolo(3,2-b)-carbazole (FICZ) is produced from tryptophan mediated by UV-light degradation and has been shown to be a strong activator of AhR (42). Furthermore, L-kynurenine, a metabolite of tryptophan utilized in the production of niacin, exhibits high affinity for AhR and has been observed to be involved in modulating immune responses (e.g. mast cell activation) (43) and promoting tumor cell survival (44). Interestingly, commensal bacteria have also been demonstrated to be involved in the production of tryptophan and appear to monitor and regulate tryptophan levels based on dietary intakes (45). Furthermore, there is evidence that certain bacteria can metabolize tryptophan into AhR ligands, such as those discussed above. For example, the bacterial species Lactobacillus reuteri (46) and Lactobacillus bulgaricus (47) are capable of producing the AhR ligand indole-3-aldehyde, which has been demonstrated to be involved in immune responses within the intestines. Additionally, indole-3-aldehyde-mediated AhR activation contributes to interleukin-22 (IL-22) transcription and mucosal responses that allow for gut microbial diversity and also protects against detrimental fungal colonization (e.g. Candida albicans) and inflammation (46). Due to the varying responses elicited by the discussed endogenous AhR ligands, further research is needed to further our understanding of the roles of AhR that extend beyond xenobiotic metabolism and the ways in which responses may be modulated for therapeutic interventions.

Cardiovascular disease and other metabolic pathologies are known to be ailments related to chronic inflammation. Importantly, recent studies have noted that AhR has functions in the regulation of immunity and inflammation (48). In support of this, AhR null mice exhibit immune system defects, including spleen enlargement and alterations in lymphocyte numbers within the spleen $(34,35)$. It also appears that AhR is important in regulating $\mathrm{T}$ cell differentiation and maintaining the balance between regulatory $\mathrm{T}$ cells and pro-inflammatory IL17-secreting $T$ cells (49). In addition to the role of AhR on $\mathrm{T}$ cells, recent studies suggest that the AhR pathway also affects B cell differentiation and antibody production (32). For example, dioxin exposure to activated B cells results in suppression of B cell differentiation, and is believed to be mediated through the AhR target Bach2 (50). Furthermore, it appears that AhR has important functions in protection against pathogenic bacterial infections, as $\mathrm{AhR}$ 
null mice display increased sensitivity to the pathogenic gram-positive bacterium Listeria monocytogenes (51).

Within the gut, AhR is highly expressed in both immune and non-immune cells and is believed to play a role in maintaining intestinal homeostasis. It has been demonstrated that activation of AhR via dietary ligands, including indole-3-carbinol, derived from the metabolism of vegetables such as broccoli and brussel sprouts, is required for the innate immune response of intraepithelial lymphocytes and IL-22-secreting lymphoid cells (52, 53). Furthermore, AhR null mice have reduced numbers of these innate immune cells, making them more vulnerable to colitis and bacterial infection (54). In mice with dextran sulfate sodium (DSS)-induced colitis, administration of the endogenous AhR ligand FICZ attenuated colitis and reduced levels of pro-inflammatory cytokine production while stimulating IL-22 production (55). Similarly, immune cells isolated from the gut of humans with Crohns disease have low expression of AhR, and treatment with AhR ligands has been demonstrated to reduce levels of proinflammatory cytokines and increase IL-22 (55).

Due to the multi-faceted role of AhR in metabolism, energy balance, and inflammation, further research on how the various endogenous and exogenous AhR ligands may differentially regulate these cellular processes is needed. Overall, it appears that the AhR signaling pathway functions more than just a xenobiotic sensor and rather is capable of integrating signals from a variety of sources to produce responses that are modifiable based on an individual's environment.

\section{Conclusion}

Exposure to persistent environmental pollutants has been associated for many years with increased risk of developing many chronic diseases including cardiovascular disease and diabetes. Using preclinical and cell culture studies, toxicologists have identified multiple causative mechanisms of toxicant-induced disease, including increased cellular oxidative stress, endocrine hormone disruption, and chronic induction of inflammation. It is now becoming clear that many enzymes and genes historically studied for their detoxification and xenobiotic-sensing capabilities may also have evolved critical endogenous processes that, if altered, can lead to metabolic dysfunction. FMO3, a well-studied drug-metabolizing enzyme, now has been shown to be critically important in the production of the cardiometabolic disease biomarker TMAO, and may also have roles in glucose and cholesterol signaling. Similarly, the dioxin-sensing transcription factor AhR has now been shown to be activated by multiple endogenous ligands, many of which are formed by the gut microbiota, and has basal roles in metabolism and energy expenditure. Interactions between toxicology, nutrition, and cardiometabolic diseases are becoming increasingly more evident, and the important endogenous roles for both AhR and FMO3 are an example of the critical necessity to reevaluate pollutant-related signaling pathways to understand previously underappreciated biological phenomena related to environmental insults and disease risks.

Research funding: This work was supported in part by the National Institute of Environmental Health Sciences at the National Institutes of Health [P42ES007380].

Conflict of interest: The authors declare that there are no competing financial interests.

\section{References}

1. Nagashima S, Shimizu M, Yano H, Murayama N, Kumai T, et al. Inter-individual variation in flavin-containing monooxygenase 3 in livers from Japanese: correlation with hepatic transcription factors. Drug Metab Pharmacokinet 2009;24(3):218-25.

2. Yamazaki M, Shimizu M, Uno Y, Yamazaki H. Drug oxygenation activities mediated by liver microsomal flavin-containing monooxygenases 1 and 3 in humans, monkeys, rats, and minipigs. Biochem Pharmacol 2014;90(2):159-65.

3. Jiang $\mathrm{Y}$, Jin J, lakova $\mathrm{P}$, Hernandez JC, Jawanmardi $\mathrm{N}$, et al. Farnesoid $\mathrm{X}$ receptor directly regulates xenobiotic detoxification genes in the long-lived Little mice. Mech Ageing Dev 2013;134(9):407-15.

4. Celius T, Pansoy A, Matthews J, Okey AB, Henderson MC, et al. Flavin-containing monooxygenase-3: induction by 3-methylcholanthrene and complex regulation by xenobiotic chemicals in hepatoma cells and mouse liver. Toxicol Applied Pharm 2010;247(1):60-9.

5. Klick DE, Shadley JD, Hines RN. Differential regulation of human hepatic flavin containing monooxygenase 3 (FMO3) by CCAAT/ enhancer-binding protein beta (C/EBPbeta) liver inhibitory and liver activating proteins. Biochem pharmacol 2008;76(2):268-78.

6. Celius T, Roblin S, Harper PA, Matthews J, Boutros PC, et al. Aryl hydrocarbon receptor-dependent induction of flavin-containing monooxygenase mRNAs in mouse liver. Drug Metab Dispos 2008;36(12):2499-505.

7. Miao J, Ling AV, Manthena PV, Gearing ME, Graham MJ, et al. Flavin-containing monooxygenase 3 as a potential player in diabetes-associated atherosclerosis. Nat Commun 2015;6:6498.

8. Zhang J, Tran Q, Lattard V, Cashman JR. Deleterious mutations in the flavin-containing monooxygenase 3 (FMO3) gene causing trimethylaminuria. Pharmacogenetics 2003;13(8):495-500.

9. Schugar RC, Brown JM. Emerging roles of flavin monooxygenase 3 in cholesterol metabolism and atherosclerosis. Curr Opin Lipidol 2015;26(5):426-31. 
10. Tang WH, Hazen SL. The contributory role of gut microbiota in cardiovascular disease. J Clin Invest 2014;124(10):4204-11.

11. Tang WH, Wang Z, Shrestha K, Borowski AG, Wu Y, et al. Intestinal microbiota-dependent phosphatidylcholine metabolites, diastolic dysfunction, and adverse clinical outcomes in chronic systolic heart failure. J Card Fail 2015;21(2):91-6.

12. Tang WH, Wang Z, Kennedy DJ, Wu Y, Buffa JA, et al. Gut microbiota-dependent trimethylamine $\mathrm{N}$-oxide (TMAO) pathway contributes to both development of renal insufficiency and mortality risk in chronic kidney disease. Circ Res 2015;116(3):448-55.

13. Bennett BJ, de Aguiar Vallim TQ, Wang Z, Shih DM, Meng Y, et al. Trimethylamine- $\mathrm{N}$-oxide, a metabolite associated with atherosclerosis, exhibits complex genetic and dietary regulation. Cell Metab 2013;17(1):49-60.

14. Wang Z, Tang WH, Buffa JA, Fu X, Britt EB, et al. Prognostic value of choline and betaine depends on intestinal microbiotagenerated metabolite trimethylamine- $\mathrm{N}$-oxide. Eur Heart J 2014;35(14):904-10.

15. Hazen SL, Brown JM. Eggs as a dietary source for gut microbial production of trimethylamine-N-oxide. Am J Clin Nutr 2014;100(3):741-3.

16. Tang WH, Wang Z, Levison BS, Koeth RA, Britt EB, et al. Intestinal microbial metabolism of phosphatidylcholine and cardiovascular risk. New Engl J Med 2013;368(17):1575-84.

17. Fogelman AM. TMAO is both a biomarker and a renal toxin. Circ Res 2015;116(3):396-7.

18. Zhu W, Gregory JC, Org E, Buffa JA, Gupta N, et al. Gut microbial metabolite TMAO enhances platelet hyperreactivity and thrombosis risk. Cell 2016;165(1):111-24.

19. Seldin MM, Meng Y, Qi H, Zhu W, Wang Z, et al. Trimethylamine $\mathrm{N}$-oxide promotes vascular inflammation through signaling of mitogen-activated protein kinase and nuclear factor-kappaB. J Am Heart Assoc 2016;5(2).

20. Warrier M, Shih DM, Burrows AC, Ferguson D, Gromovsky $A D$, et al. The TMAO-generating enzyme flavin monooxygenase 3 is a central regulator of cholesterol balance. Cell Rep 2015;10(3):326-38.

21. Shih DM, Wang Z, Lee R, Meng Y, Che N, et al. Flavin containing monooxygenase 3 exerts broad effects on glucose and lipid metabolism and atherosclerosis. J Lipid Res 2015;56(1):22-37.

22. Kewley RJ, Whitelaw ML, Chapman-Smith A. The mammalian basic helix-loop-helix/PAS family of transcriptional regulators. Int J Biochem Cell Biol 2004;36(2):189-204.

23. Quintana FJ. The aryl hydrocarbon receptor: a molecular pathway for the environmental control of the immune response. Immunology 2013;138(3):183-9.

24. Liu D, Perkins JT, Petriello MC, Hennig B. Exposure to coplanar PCBs induces endothelial cell inflammation through epigenetic regulation of NF-kappaB subunit p65. Toxicol Appl Pharm 2015;289(3):457-65.

25. Perkins JT, Petriello MC, Newsome BJ, Hennig B. Polychlorinated biphenyls and links to cardiovascular disease. Environ Sci Pollut Res Int 2016;23(3):2160-72.

26. Petriello MC, Han SG, Newsome BJ, Hennig B. PCB 126 toxicity is modulated by cross-talk between caveolae and Nrf2 signaling. Toxicol Appl Pharm 2014;277(2):192-9.

27. Schlezinger JJ, Struntz WD, Goldstone JV, Stegeman JJ. Uncoupling of cytochrome P450 $1 \mathrm{~A}$ and stimulation of reactive oxygen species production by co-planar polychlorinated biphenyl congeners. Aquat Toxicol 2006;77(4):422-32.
28. Majkova Z, Smart E, Toborek M, Hennig B. Up-regulation of endothelial monocyte chemoattractant protein-1 by coplanar PCB77 is caveolin-1-dependent. Toxicol Applied Pharm 2009;237(1):1-7.

29. Lim EJ, Majkova Z, Xu S, Bachas L, Arzuaga X, et al. Coplanar polychlorinated biphenyl-induced CYP1A1 is regulated through caveolae signaling in vascular endothelial cells. Chem-Biol Interact 2008;176(2-3):71-8.

30. Gambier N, Marteau JB, Batt AM, Marie B, Thompson A, et al. Interaction between CYP1A1 T3801C and AHR G1661A polymorphisms according to smoking status on blood pressure in the Stanislas cohort. J Hypertens 2006;24(11):2199-205.

31. Lanca V, Alcantara P, Braz-Nogueira J, Bicho MP. Cytochrome P450 1A1 (CYP1A1) T6325C polymorphism might modulate essential hypertension-associated stroke risk. Rev Port Cardiol 2004;23(3):343-55.

32. Tian J, Feng Y, Fu H, Xie HQ, Jiang JX, et al. The aryl hydrocarbon receptor: a key bridging molecule of external and internal chemical signals. Environ Sci Technol 2015;49(16):9518-31.

33. Mimura J, Yamashita K, Nakamura K, Morita M, Takagi TN, et al. Loss of teratogenic response to 2,3,7,8-tetrachlorodibenzo-pdioxin (TCDD) in mice lacking the Ah (dioxin) receptor. Genes Cells 1997;2(10):645-54.

34. Schmidt JV, Su GH, Reddy JK, Simon MC, Bradfield CA. Characterization of a murine Ahr null allele: involvement of the Ah receptor in hepatic growth and development. Proc Natl Acad Sci USA 1996;93(13):6731-6.

35. Fernandez-Salguero P, Pineau T, Hilbert DM, McPhail T, Lee SS, et al. Immune system impairment and hepatic fibrosis in mice lacking the dioxin-binding Ah receptor. Science 1995;268(5211):722-6.

36. Girer NG, Murray IA, Omiecinski CJ, Perdew GH. Hepatic aryl hydrocarbon receptor attenuates fibroblast growth factor 21 expression. The J Biol Chem 2016;291(29):15378-87.

37. Lu P, Yan J, Liu K, Garbacz WG, Wang P, et al. Activation of aryl hydrocarbon receptor dissociates fatty liver from insulin resistance by inducing fibroblast growth factor 21. Hepatology 2015;61(6):1908-19.

38. Thackaberry EA, Bedrick EJ, Goens MB, Danielson L, Lund AK, et al. Insulin regulation in AhR-null mice: embryonic cardiac enlargement, neonatal macrosomia, and altered insulin regulation and response in pregnant and aging AhR-null females. Toxicol Sci 2003;76(2):407-17.

39. Xu CX, Wang C, Zhang ZM, Jaeger CD, Krager SL, et al. Aryl hydrocarbon receptor deficiency protects mice from dietinduced adiposity and metabolic disorders through increased energy expenditure. Int J Obesity 2015;39(8):1300-9.

40. Baker NA, Shoemaker R, English V, Larian N, Sunkara M, et al. Effects of adipocyte aryl hydrocarbon receptor deficiency on PCB-induced disruption of glucose homeostasis in lean and obese mice. Environ Health Perspect 2015;123(10):944-50.

41. Barouki R, Coumoul X, Fernandez-Salguero PM. The aryl hydrocarbon receptor, more than a xenobiotic-interacting protein. FEBS Lett 2007;581(19):3608-15.

42. Rannug U, Rannug A, Sjoberg U, Li H, Westerholm R, et al. Structure elucidation of two tryptophan-derived, high affinity Ah receptor ligands. Chem Biol 1995;2(12):841-5.

43. Kawasaki H, Chang HW, Tseng HC, Hsu SC, Yang SJ, et al. A tryptophan metabolite, kynurenine, promotes mast cell activation through aryl hydrocarbon receptor. Allergy 2014;69(4):445-52. 
44. Opitz CA, Litzenburger UM, Sahm F, Ott M, Tritschler I, et al. An endogenous tumour-promoting ligand of the human aryl hydrocarbon receptor. Nature 2011;478(7368):197-203.

45. Sarsero JP, Merino E, Yanofsky C. A Bacillus subtilis operon containing genes of unknown function senses tRNATrp charging and regulates expression of the genes of tryptophan biosynthesis. Proc Natl Acad Sci USA 2000;97(6):2656-61.

46. Zelante T, Iannitti RG, Cunha C, De Luca A, Giovannini G, et al. Tryptophan catabolites from microbiota engage aryl hydrocarbon receptor and balance mucosal reactivity via interleukin-22. Immunity 2013;39(2):372-85.

47. Takamura T, Harama D, Fukumoto S, Nakamura Y, Shimokawa N, et al. Lactobacillus bulgaricus OLL1181 activates the aryl hydrocarbon receptor pathway and inhibits colitis. Immunol Cell Biol 2011;89(7):817-22.

48. Stevens EA, Mezrich JD, Bradfield CA. The aryl hydrocarbon receptor: a perspective on potential roles in the immune system. Immunology 2009;127(3):299-311.

49. Quintana FJ, Basso AS, Iglesias AH, Korn T, Farez MF, et al. Control of $\mathrm{T}(\mathrm{reg})$ and $\mathrm{T}(\mathrm{H}) 17$ cell differentiation by the aryl hydrocarbon receptor. Nature 2008;453(7191):65-71.

50. De Abrew KN, Phadnis AS, Crawford RB, Kaminski NE, Thomas RS. Regulation of Bach2 by the aryl hydrocarbon receptor as a mechanism for suppression of B-cell differentiation by 2,3,7,8-tetrachlorodibenzo-p-dioxin. Toxicol Applied Pharm 2011;252(2):150-8.

51. Shi LZ, Faith NG, Nakayama Y, Suresh M, Steinberg H, et al. The aryl hydrocarbon receptor is required for optimal resistance to Listeria monocytogenes infection in mice. J Immunol 2007;179(10):6952-62.

52. Kiss EA, Vonarbourg C, Kopfmann S, Hobeika E, Finke D, et al. Natural aryl hydrocarbon receptor ligands control organogenesis of intestinal lymphoid follicles. Science 2011;334(6062):1561-5.

53. Lee JS, Cella M, McDonald KG, Garlanda C, Kennedy GD, et al. AHR drives the development of gut ILC22 cells and postnatal lymphoid tissues via pathways dependent on and independent of Notch. Nat Immunol 2012;13(2):144-51.

54. Monteleone I, MacDonald TT, Pallone F, Monteleone G. The aryl hydrocarbon receptor in inflammatory bowel disease: linking the environment to disease pathogenesis. Curr Opin Gastroen 2012;28(4):310-3.

55. Monteleone I, Rizzo A, Sarra M, Sica G, Sileri P, et al. Aryl hydrocarbon receptor-induced signals up-regulate IL-22 production and inhibit inflammation in the gastrointestinal tract. Gastroenterology 2011;141(1):237-48, 48 e1. 